Review Article

\title{
Food Fortification and Dietary Diversification as Effective Interventions to Improve Iron Status of Indian Population
}

\author{
K MADHAVAN NAIR $^{1, *}$ and LITTLE FLOWER AUGUSTINE ${ }^{2}$ \\ ${ }^{1}$ National Institute of Nutrition, Indian Council of Medical Research, Hyderabad, Telangana and Vice- \\ President, Nutrition Society of India \\ ${ }^{2}$ TATA-NIN Centre for Excellence in Public Health Nutrition, National Institute of Nutrition, Indian Council \\ of Medical Research, Hyderabad, Telangana
}

(Received on 22 June 2018; Accepted on 04 July 2018)

\begin{abstract}
In developed countries, strategies such as supplementation and staple food fortification have proved to be successful for the control of anaemia. However, while translating these strategies to other situations, several factors which are specific to the location need critical analysis and consideration. The three major contextual elements of iron bioavailability which need critical analysis in the Indian context are (1) the host's gastric acid milieu for iron solubilisation (2) the ability of habitual diet to keep iron in a soluble state throughout the intestinal absorptive surface by balancing the relative proportion of inhibitors and promoters and (3) the hepcidin-(iron regulatory protein) mediated inhibition of iron from daily iron supplementation. In India, where severe forms of deficiencies have been already addressed, food fortification appears to be a promising step forward. Simple dietary diversification strategies such as including iron-rich foods and vitamin-C rich fruits in habitual meals (to enhance iron absorption) would be synergistic to the efforts aimed at food fortification. This has been established by feeding trials with papaya and guava. The relatively larger gap between demand and supply among vulnerable segment of population could be addressed by introducing point of use fortification with multiple micronutrient powders (MNP). Thus, scaling-up of these two strategies may not only build iron stores but also speed up the process of recovery from anaemia and can prove to be effective interventions in India.
\end{abstract}

Keywords: Fortitication; Diversification; Interventions; Iron Status

\section{Introduction}

Lack of bioavailable iron in the habitual Indian diets, increased iron demand, particularly during rapid growth, pregnancy, physiological blood loss caused by menstruation, and excess blood loss caused by pathologic infections such as hook worm infestation, are the major causes of high prevalence of iron deficiency anaemia (IDA) among the vulnerable segments of the Indian population. Due to nonaffordability of iron-rich foods, especially those of animal origin, containing more bioavailable haeme iron, India has adopted universal iron supplementation programme to the vulnerable groups (NIPI, 2015; WHO, 2016).

Experience from the past four decades indicates that there are two problems with iron supplementation programmes: a low outreach, and the possibility of potential side effects (Peña-Rosas and Viteri, 2009). Adverse events in African children of malariaendemic regions receiving iron during a very large intervention trial raised serious concerns about the pan administration of iron supplements (Sazawal et al., 2006). Subsequent studies have established this (Soofi et al., 2013 and Zolkins et al., 2013). The effect of excess iron appears to be on potentiating the number of pathogenic bacteria and protozoa in the gut (Moretti et al., 2015, Paganini et al., 2017, Paganini and Zimmermann, 2017).

Food fortification appears to be a promising strategy if the severe forms of deficiency have been already addressed. Staple food fortification has been

*Author for Correspondence: E-mail: nairthayil@gmail.com 
practiced across the globe and to a great extent iron deficiency anaemia has been kept under control in many developed countries (Pachón et al., 2015, Athe et al., 2013). In India, several contextual factors need to be considered while providing iron through fortified foods: (1) the host's gastric acid milieu for iron solubilisation and (2) the concurrent ability of the habitual diet to keep iron in a soluble state throughout the intestinal absorptive surface by balancing the relative proportion of inhibitors and promoters and (3) the hepcidin-mediated inhibition of iron from daily iron supplementation with large doses and consequently the relevance of consumption of iron- fortified food during the periods of iron supplementation.

The purpose of this review is to critically assess the latest evidence on these contextual factors and suggest food-based strategies for increasing the intake of bioavailable iron.

\section{Dietary Iron Bioavailability and Factors Influencing Iron Absorption}

\section{Dietary Iron Bioavailability}

There are only two studies that assessed bioavailability of iron from a typical habitual meal in Indians using stable isotopic method. A study among 18-35-y-old women has reported iron bioavailability ranging from 5.2-9.4\% in non-iron-deficient and 15.6-19.7\% in irondeficient subjects (Thankachan et al., 2008). A study in adolescent boys and girls of 13-15 years old, reported iron bioavailability of 9.7\% (95\% CI: 6.1, 13.3) in girls and $8.6 \%(95 \% \mathrm{CI}: 6.2,11.0)$ in boys, which is similar to the range of values reported in non-iron deficient women above (Nair et al., 2013).

\section{Mechanism of Iron Absorption and Factors Influencing Iron Absorption}

In contrast to most of the nutrient balances, iron is considered to be regulated at the site of absorption. The absorption of dietary non-haeme iron is carried out by mature villus enterocytes of the duodenum and proximal jejunum. The gastric acid production plays a key role in solubilising iron (Conrad and Schade, 1968). At the absorptive surface, iron must be in its ferrous form to be taken up by the enterocyte. A ferric reductase enzyme on the brush border does this function. A divalent metal transporter (DMT 1) transports the iron across the membrane into the cell.
Once inside the cell, iron is either stored in ferritin or exported by the iron exporter ferroportin 1 (FPN-1) hepcidin mediated process on the baso-lateral side of the enterocyte. Iron is oxidized back to the ferric form by the ferroxidase, hephaestin and ceruloplasmin and loaded onto transferrin and circulated through the blood (Knutson, 2017).

A variety of factors including variations in body iron stores, changes in the rate of erythropoiesis, hypoxia, inflammation, and pregnancy, influence the amount of iron absorbed by enterocytes. These factors induce production of major enterocyte iron transporters, such as DMT1, Dcytb, and ferroportin 1, at both the mRNA level and protein level (Frazer and Anderson, 2005).

\section{Dietary Iron Critical for Iron Stores During the Life Cycle}

About $90 \%$ of daily iron needs (20 mg per day) are obtained by the iron recycling process through the breakdown of haeme-iron in red blood cells (RBC). In adult men, approximately $95 \%$ of the iron required for the production of red blood cells is recycled from the breakdown of RBCs and only 5\% comes from dietary sources. In contrast, an infant is estimated to derive approximately $70 \%$ of iron from the breakdown of RBCs and $30 \%$ from the diet. In the diet of an infant, before the introduction of solid foods, the amount of iron absorbed depends on the amount and bioavailability of iron in breast milk or formula (ICMR, 2010).Due to these processes, the major factors affecting iron balance are the iron lost and stored in the body and the sum of these two is the iron requirement (Table-1).Iron stores have a dominant role in regulating the rate of absorption and exhibit a close inverse relationship between serum ferritin and non-haeme iron absorption. Therefore, to establish an iron balance we need to implement strategies that build-up adequate iron stores.

The vulnerable segments of the Indian population predominantly suffer from iron deficiency anaemia with little or no body iron stores (Nair et al., 2016 and Nair et al., 2018). This may be due to the presence of multiple factors associated with anaemia which are operating in Indian context such as high rate of low birth weight (LBW), under nutrition, stunting, low grade infection, epidemiological transition and poor bio-availability of iron from their habitual diets limiting 
the scope for establishing iron stores as the age advances. Absorption studies with low dose $(30 \mathrm{mg})$ iron taken during fasting by men and women of different iron status strongly suggest that build-up of iron stores was much lower from iron supplements than from dietary iron (Hallberg, 1995). Thus, the dietary iron maybe more critical than high doses of iron supplements for building iron stores during the life cycle.

\section{Iron Requirement and Recommended Dietary Allowances Through Life Cycle}

The foundation of adequate iron status is laid before
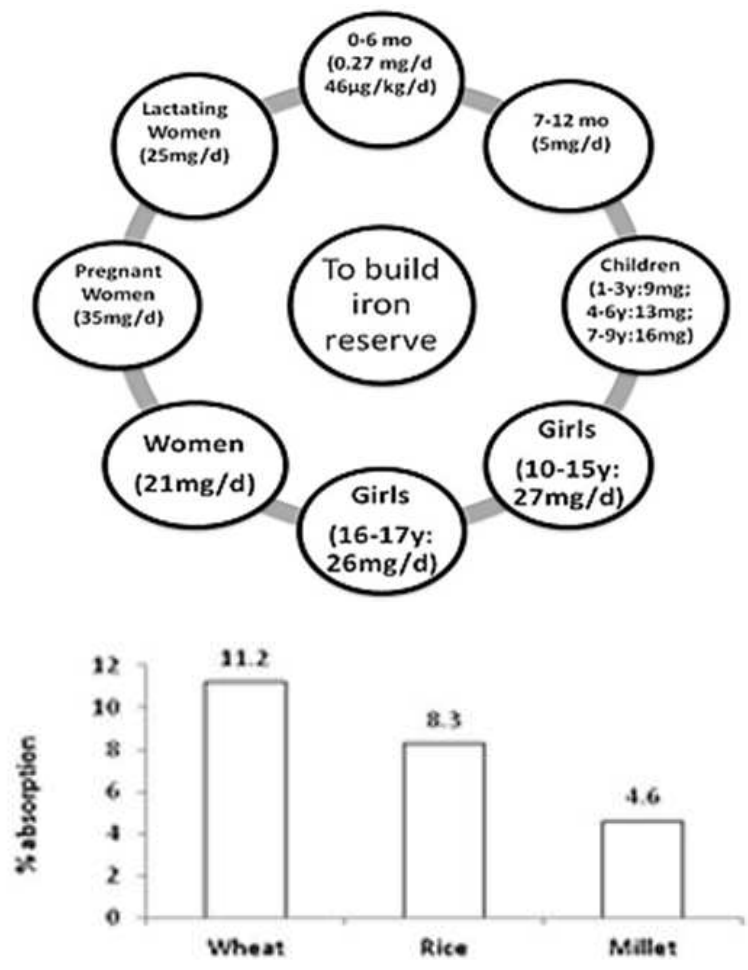

Iron absorption in iron deficient women

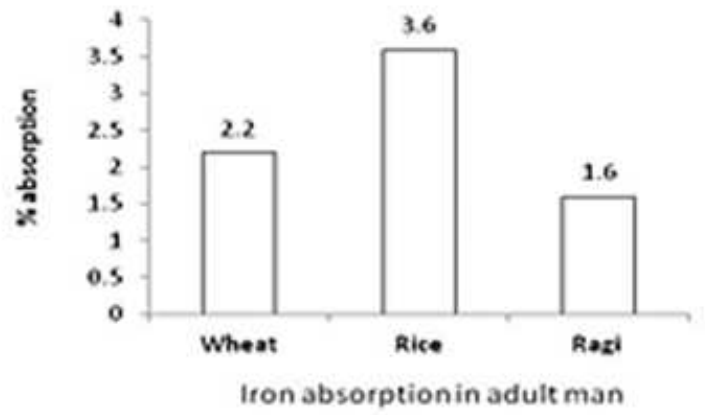

Fig. 1: Recommended dietary allowances (RDA) of iron throughout the life cycle and the influence of host and dietary factors in determining iron bioavailability birth, during childhood, and is followed during adolescence. Iron requirement is a function of iron loss + that required for increased demand during growth + that required for storage (Table 1). It increases with physiological status and reaches a peak of about $3 \mathrm{mg} /$ day during pregnancy. Iron requirements are met from a habitual diet that satisfies the iron content and absorption. Meeting iron requirement is a prerequisite for preventing iron deficiency throughout the life cycle which is a function of iron absorption (ICMR, 2010).

Figure 1 depicts the recommended dietary allowances (RDA) of iron throughout life cycle. The influence of host and dietary factors in determining iron absorption considered in computing RDA of iron for Indians were $5 \%$ for all age and gender groups and $8 \%$ for women (ICMR 2010).

The Host's Gastric Acid Milieu for Iron Solubilisation and the Influence of Inhibitors/ Promoters in Iron Absorption

Haeme iron derived from meat, poultry and fish, is two to three times more absorbable than non-haeme iron, which is found in plant-based foods and ironfortified foods (Hurrell and Egli, 2010). Bioavailability of non-haeme iron depends on dietary composition i.e. to keep iron in a soluble state throughout the intestinal absorptive surface by balancing the relative proportion of inhibitors and promoters. The chemical reaction that aids in this is: dietary iron which is in $\mathrm{Fe}^{3+}$ form at acidic conditions and is chelated with food ligands which are either enhancers or inhibitors of iron absorption. Number of dietary ligands have been identified which limit the absorption of iron. These can be classified as food sources that contain (1) tannins or polyphenols present in tea and vegetables and (2) phytates present in the outer coat of whole grains. The most powerful promoters of non-haeme iron absorption is vitamin $\mathrm{C}$. Vitamin $\mathrm{C}$ being a reducing agent converts $\mathrm{Fe}^{3+}$ to $\mathrm{Fe}^{2+}$ and forms soluble chelates. The less powerful promoters are citric acid, tartaric acidand lactic acid.

Typically, Indian diets are categorized as low iron bioavailable diets (5-8\%) being high in inhibitors and low in promoters (Rao and Prabhavathi 1978; Nair and Iyengar, 2009and Kalasuramath et al., 2013). We need to create an environment conducive 
Table 1: Basis for computing iron requirements during adolescence: Iron loss on account of obligatory and menstrual blood loss and iron needs for blood volume expansion, increase in muscle mass and storage (ICMR, 2010)

\begin{tabular}{lccccccc}
\hline Age group (y) & $\begin{array}{c}\text { Body wt } \\
(\mathrm{kg})\end{array}$ & $\begin{array}{c}\text { Obligatory } \\
\text { loss }(\mathrm{mg} / \mathrm{d})\end{array}$ & $\begin{array}{c}\text { Menstrual } \\
\text { blood loss } \\
(\mathrm{mg} / \mathrm{d})\end{array}$ & $\begin{array}{c}\text { Blood vol. } \\
\text { expansion } \\
(\mathrm{mg} / \mathrm{d})\end{array}$ & $\begin{array}{c}\text { Increase in } \\
\text { muscle(mg/d) }\end{array}$ & $\begin{array}{c}\text { Allowance for } \\
\text { store(mg/d) }\end{array}$ & $\begin{array}{c}\text { Total requirement } \\
(\mathrm{mg} / \mathrm{d})\end{array}$ \\
\hline $10-12$ Boys & 34.3 & 0.49 & - & 0.27 & 0.13 & 0.16 & 1.05 \\
Girls & 35.0 & 0.49 & 0.28 & 0.27 & 0.13 & 0.16 & 1.33 \\
$13-15$ Boys & 47.6 & 0.66 & - & 0.39 & 0.15 & 0.40 & 1.60 \\
Girls & 46.6 & 0.65 & 0.37 & 0.13 & 0.06 & 0.15 & 1.36 \\
16-17 Boys & 55.4 & 0.78 & - & 0.14 & 0.05 & 0.40 & 1.37 \\
Girls & 52.1 & 0.73 & 0.42 & - & - & 0.15 & 1.30 \\
\hline
\end{tabular}

for only $\mathrm{Fe}^{2+}$ form of iron to the absorptive cells of the intestine. This can be facilitated by the simultaneous presence of vitamin $\mathrm{C}$ and other organic acids and non-haeme iron which not only provide a medium for reducing iron to ferrous form but also in reversing the inhibitory effects of polyphenols and phytates (Hallberg, 1989). Thus, if the physiological system can increase the ferrous iron pool at the absorptive surface, uptake process of iron will be more facilitated.

\section{Role of Vitamin C in Iron Absorption}

Presence of iron and vitamin $\mathrm{C}$ at the gastric $\mathrm{pH}$ of the stomach is very critical for vitamin $\mathrm{C}$ to act as a promoter of iron absorption. It has been shown in vitro that the chemical reaction of ferric chloride and vitamin $\mathrm{C}$ must be initiated at an acid $\mathrm{pH}$ to ensure solubility of iron at $\mathrm{pH}$ of the duodenum (Conrad $\mathrm{M}$ and Schade, 1968). In this reaction, iron displaces $\mathrm{H}$ ions from ascorbic acid to form purple colour complexes which are soluble over a wide range of $\mathrm{pH}$ of 2-11. An exponential increase in iron absorption was observed with the addition of vitamin $\mathrm{C}$ in a meal, though degree of increase varied with the food matrix of the meal (Cook, 1977). Vitamin C was shown to be more effective when consumed with meal rather than taking it 4-8 hours before the meal intake. Using human intestinal cell line Caco 2 cells, the inhibitory effect of phytate and enhancing effect of vitamin $\mathrm{C}$ on iron absorption from pea ferritin iron was shown (Bejjani et al,. 2007).

A very strong, exponential relationship $(\mathrm{r}=0.99)$ was found between the amount of phytate added and the inhibition of the iron absorption (Hallberg, 1989). An addition of $50 \mathrm{mg}$ and $100 \mathrm{mg}$ vitamin $\mathrm{C}$ in a meal containing $25 \mathrm{mg}$ phytate were found to increase the absorption about twice and 3-4 times respectively. A complete inhibitory neutralization effect can be established at the level of $80 \mathrm{mg}$ ascorbic acid. Similarly the role of vitamin C in overcoming inhibitory effect of tannic acid and complete neutralization effect at a concentration of $100 \mathrm{mg}$ were reported (Siegenberg, 1991). A threefold improvement in iron absorption from a Thai meal was established using a fruit mix of papaya, banana and orange containing 35 $\mathrm{mg}$ ascorbic acid per portion (Björn-Rasmussen et al., 1974). Similarly, $150 \mathrm{~g}$ papaya was found to enhance non-haeme iron absorption from a maizebased meal by almost five times in 13 healthy Venezuelean adults using radio labelled iron. The absorption enhancement factor of papaya was established when identical increase in iron absorption was demonstrated with $70 \mathrm{mg}$ synthetic ascorbic acid, the quantity of vitamin $\mathrm{C}$ estimated in $150 \mathrm{~g}$ papaya (Layrisse et al., 1974). An increase in iron absorption from $2.5 \%$ to $12.6 \%$ was reported by feeding $100 \mathrm{~g}$ of fresh guava and papaya along with a meal consisting of cooked rice, margarine and sucrose to Indian housewives in Durban (Ballot et al., 1987). Using stable isotopic dilution method among 13-15 year adolescent boys and girls, inclusion of $100 \mathrm{~g}$ guava was demonstrated to increase bioavailability of iron by two folds ( $9.7 \pm 6.5 \%$ to $23.9 \pm 11.2 \%$ in boys and $8.6 \pm 4.1 \%$ to $19.2 \pm 8.4 \%$ in girls) from habitual ricebased Indian meal (Nair et al., 2013).

A 30 day intervention trial involving feeding 100 g guava fruit with wheat based lunch and dinner meals (vitamin C in experimental diet $232 \mathrm{mg} / \mathrm{meal}$, control $25 \mathrm{mg} / \mathrm{meal}$ ) among 40 young women, resulted in a net increase of $1.9 \mathrm{~g} / \mathrm{dL}$ haemoglobin in fruit supplemented group (from $10.7 \mathrm{~g} / \mathrm{dL}$ to $12.9 \mathrm{~g} / \mathrm{dL}$ ) in comparison with the control (from $11.0 \mathrm{~g} / \mathrm{dL}$ to $11.3 \mathrm{~g}$ / 
dL) (Arora et al., 1991). A randomized control trial among 6-10y children demonstrated an increase of $0.37 \mathrm{~g} / \mathrm{dL}$ haemoglobin after 7 months regular consumption of $70 \mathrm{~g}$ guava with mung bean based supplementary meal (Rani et al., 2013). However, guava juice $(300 \mathrm{~mL})$ providing $200 \mathrm{mg}$ ascorbic acid given with wheat based institutional lunch meal to 69 year old anaemic children $(\mathrm{N}=95)$ for 10 weeks found a marginal effect on haemoglobin and ferritin concentrations $(0.64 \mathrm{~g} / \mathrm{dL}$ higher $\mathrm{Hb}$ and $2.47 \mathrm{ng} / \mathrm{mL}$ higher ferritin compared with the placebo) in children consuming high-phytate diets fortified with iron (Monarrez-Espino et al., 2011).

Most of these studies have demonstrated that the bioavailability of iron can be doubled with the inclusion of a vitamin $\mathrm{C}$ rich fruit in habitual meals. Quantitatively, the ratio of phytate to iron should be $<0.4: 1$ or vitamin $\mathrm{C}$ to iron of $>4: 1$ to significantly improve iron absorption in cereal- legume based meals (Hurrell and Egli, 2010). These evidences can form the basis of formulating dietary guidelines.

\section{Concurrent Use of Supplementation and Fortification: The Role of Hepcidin}

Unlike supplementation, iron fortification at the point of manufacture enables the delivery of small doses of iron in a food vehicle along side the possibility of several servings per day. It is slower to raise body iron levels compared with iron supplementation or iron therapy, but it might be safer. In India, the food fortification programmes are on a rise, providing up to one RDA level of iron (17 mg/day) in different food stuffs (FSSAI, 2017).

Globally, food fortification at the point of use through multiple micronutrient powders (MNP) is yet another strategy of proven benefit. Interventions with MNPs were efficacious in terms of reducing anaemia and iron deficiency in preschool children (DeRegil et al., 2017) and therefore appear to be a promising strategy to invest for the next five years, but after appropriate research related to its implementation (WHO, 2011).

Hepcidin, the iron regulatory hormone, regulates intestinal iron absorption, plasma iron concentrations, and tissue iron distribution by inducing degradation of its receptor, the cellular iron exporter ferroportin (Nemeth and Ganz, 2009). Hepcidin, a 25 amino acid cysteine-rich peptide, is secreted by liver and its main site of action is cellular iron transporter, ferroportin. Hepcidin responds to various stimuli including hypoxia, and inflammatory response such as IL-6. It has an inverse relation with iron absorption.

\section{Oral Iron Supplements Increase Hepcidin and Decrease Iron Absorption}

Recent studies have shown that circulating hepcidin inhibits iron absorption from consecutive iron supplementation regimen above $60 \mathrm{mg} /$ day. This conclusion is based on a series of trials with iron supplementation as per the WHO guidelines.

In a dose-finding trial, among non-anaemic though iron-depleted young women, a six fold increase in iron dose (40 to $240 \mathrm{mg}$ ) resulted in only a threefold increase in iron absorption (6.7-18.1 mg). Subsequent iron absorption study from 3 doses of iron in 24 hours ( 2 mornings and an afternoon, $60 \mathrm{mg}$ dose) showed that the total iron absorbed from 3 doses was not significantly greater than that from 2 morning doses and was related to an increase in serum hepcidin levels (Moretti et al., 2015). In line with this acute dose study, a randomized controlled trial among women aged 18-40 years (60 mg iron on consecutive days for 14 days vs. the same doses on alternate days for 28 days) showed higher serum hepcidin in the consecutive-day group than the alternate-day group (Stoffel et al., 2017). These studies clearly indicate an inhibitory role of hepcidin during daily iron supplementation dose above $60 \mathrm{mg}$ per day.

In India, National Iron Plus Initiative guidelines suggest $100 \mathrm{mg}$ of iron per day for 100days (NIPI, 2015). A lack of drastic improvement in iron status of population with this dose regimen could be due to the hepcidin mediated inhibition of iron absorption from consecutive doses. Though fortification is theoretically the right transition for India for tackling the less-severe forms of iron deficiency, the point to ponder is, whether in this background, a fortification programme which provides an additional 0.5 to one RDA would be of any benefit to the population if the inhibitory mechanisms are operating due to simultaneous administration of high dose iron supplements and fortification in different population groups.

In addition to the pathway of iron load, hepcidin operates through inflammatory pathway as well. In 
cases of inflammation, hepcidin is released independent of iron intake and thereby inhibits iron absorption and iron release creating a pseudodeficiency state. This demands a more comprehensive strategy for targeting iron deficiency wherein not only iron is provided but the background is cleared of inflammation and iron overload. An integration of Nutrition and Water, sanitation and hygiene (WASH) interventions is therefore warranted.

\section{Conclusion}

In the Indian context, control and prevention of iron

\section{References}

Arora S, Anbarsi RA and Seshadri S (1991) Chemical composition of some seasonal fruits of India: Effects on iron availability from a cereal meal, Abstracts, Nutrition Society of India 32

Athe R, Rao M V V and Nair K M (2013) Impact of iron fortified foods on $\mathrm{Hb}$ concentration in children $(<10 \mathrm{yrs})$ : a systematic review and meta-analysis of randomized controlled trials Public Health Nutrition 17 579-586

Ballot D, Baynes R, Bothwell T, Gillooly M, Macfarlane J, MacPhail A, Lyons G, Derman D, Bezwoda W and Torrance J (1987) The effects of fruit juices and fruits on the absorption of iron from a rice meal British Journal of Nutrition 57 331-343

Bejjani S, Pullakhandam R, Punjal R and Nair K M (2007) Gastric digestion of pea ferritin and modulation of its iron bioavailability by ascorbic and phytic acids in caco- 2 cells World Journal of Gastroenterology 13 2083-2088

Conrad M and Schade S G (1968) Ascorbic acid chelates in iron absorption: a role for hydrochloric acid and bile Gastroenterology 55 35-45

De-Regil L M, Jefferds M E D and Pena-Rosas J P (2017) Pointof-use fortification of foods with micronutrient powders containing iron in children of preschool and school-age Cochrane Database of Systematic Reviews 11

Frazer D M and Anderson G J (2005) Iron Imports. I. Intestinal iron absorption and its regulation. American Journal of Physiology-Gastrointestinal and Liver Physiology 289 G631-G635

FSSAI (2017) Food Safety Standards Authority of India. Large Scale Food Fortification in India The Journey So Far and Road Ahead. Food Fortification Resource Centre, Food safety and standards authority of India. Ministry of Health and Family Welfare, GoI, New Delhi deficiency requires addressing the twin determinants; enhancing iron content and simultaneously improving the bioavailability of added iron through food synergy. Inclusion of vitamin $\mathrm{C}$ rich fruits in the habitual diets of population has been shown to establish the food synergy for doubling the iron absorption. Other strategies that need to dove tail are strategies to reduce worm infestation including making India free of open defecation and creating an enabling environment for the provision of WASH, and public awareness. These are the real challenges facing the nation.

Hallberg L (1995) Iron absorption from diet and tablets Scandinavian Journal of Nutrition 39 20-26

Hallberg L, Brune M and Rossander L (1989) Iron absorption in man: ascorbic acid and dose-dependent inhibition by phytate American Journal of Clinical Nutrition 49 140144

Hurrell R and Egli I (2010) Iron bioavailability and dietary reference values American Journal of Clinical Nutrition 91 $1461 \mathrm{~s}-1467 \mathrm{~s}$

ICMR (2010) Indian Council of Medical Research. Nutrient requirements and recommended dietary allowances for Indians. In A report of the expert group of the Indian Council of Medical Research 2010, National Institute of Nutrition, Hyderabad, India

Kalasuramath S, Kurpad A V and Thankachan P (2013) Effect of iron status on iron absorption in different habitual meals in young south Indian women Indian Journal of Medical Research 137 324-330

Knutson M D (2017) Iron transport proteins: gateways of cellular and systemic iron homeostasis. Journal of Biological Chemistry 292 12735-12743

Layrisse M, Martínez-Torres C and González M (1974) Measurement of the total daily dietary iron absorption by the extrinsic tag model American Journal of Clinical Nutrition 27 152-162

Monarrez-Espino J, Lopez-Alarcon M and Greiner T (2011) Randomized placebo-controlled trial of guava juice as a source of ascorbic acid to reduce iron deficiency in Tarahumara indigenous schoolchildren of northern Mexico Journal of the American College of Nutrition 30 191-200

Moretti D, Goede JS, Zeder C, Jiskra M, Chatzinakou V, Tjalsma H, Melse-Boonstra A, Brittenham G, Swinkels D W and Zimmermann M B (2015) Oral iron supplements increase 
hepcidin and decrease iron absorption from daily or twicedaily doses in iron-depleted young women Blood 126 19811989

Nair K M, Brahmam G N V, Radhika M S, Dripta R C, Ravinder P, Balakrishna N, Chen Z, Keli H M and Abrams S A (2013) Inclusion of guava enhances non-heme iron bioavailability but not fractional zinc absorption from a rice based meal in adolescents Journal of Nutrition 143 852-858.

Nair K M, Dripta R C and Konapur A (2018) Appropriate doses of iron for treatment of anemia amongst Indian Journal of Community Health 30 Supp: 39-53

Nair K M and Iyengar V (2009) Iron content, bioavailability and factors affecting iron status of Indians Indian Journal of Medical Research 130 634-645

Nair K M, Fernandez-Rao S, Nagalla B, Kankipati R V, Punjal R, Augustine L F, Hurley K M, Nicholas T, Harding K B, Greg R and Black M M (2016) Characterization of anaemia and associated factors among infants and pre-schoolers from rural India Public Health Nutrition 19 861-871

Rao B S N and Prabhavathi T (1978) An in vitro method for predicting the bioavailability of iron from foods American Journal of Clinical Nutrition 31 169-175

Nemeth E and Ganz T (2009) The role of hepcidin in iron metabolism Acta Haematologica 122 78-86

NIPI (2015) National iron plus initiative for anaemia control among Indian population (NIPI). Ministry of Health and Family Welfare. Government of India

Pachón H, Spohrer R, Mei Z and Serdula M K (2015) Evidence of the effectiveness of flour fortification programs on iron status and anemia: a systematic review Nutrition Reviews 73 780-95

Paganini D and Zimmermann M B (2017) The effects of iron fortification and supplementation on the gut microbiome and diarrhoea in infants and children: a review American Journal of Clinical Nutrition 106 Suppl: 1688S-93S

Paganini D, Uyoga M A, Kortman G A M, Cercamondi C I, Moretti D, Barth-Jaeggi T, Schwab C, Boekhorst J, Timmerman H M, Lacroix C, Karanja S and Zimmermann M B (2017) Prebioticgalacto-oligosaccharides mitigate the adverse effects of iron fortification on the gut microbiome: A randomised controlled study in Kenyan infants Gut $\mathbf{6 6}$ 1956-1967

Pena-Rosas J P and Viteri F E (2009) Effects and safety of preventive oral iron or iron+folic acid supplementation for women during pregnancy (Review) Cochrane Database of Systematic Reviews $\mathbf{4}$

Rani V, Moretti D, Khetarpaul N, Zimmerman M B, Jood S and Brouwer I D (2013) Vitamin C from guava consumed with mungbean with modest native iron increases available iron for erythropoiesis and hemoglobin but not iron stores Annals of Nutrition and Metabolism 631715

Sazawal S, Black R E, Kabole I, Dutta A, Dhingra U and Ramsan M (2014) Effect of iron/folic acid supplementation on the outcome of malaria episodes treated with sulfadoxinepyrimethamine Malaria Research and Treatment 1-5

Siegenberg D, Baynes R D, Bothwell T H, Macfarlane B J, Lamparelli R D, Car N, MacPhail P, Schmidt U, Tal A and Mayet F (1991) Ascorbic acid prevents the dose-dependent inhibitory effects of polyphenols and phytates on nonheme-iron absorption The American Journal of Clinical Nutrition $\mathbf{5 3}$ 537-541

Soofi S, Cousens S, Iqbal S P, Akhund T, Khan J, Ahmed I, Zaidi A K and Bhutta Z A (2013) Effect of provision of daily zinc and iron with several micronutrients on growth and morbidity among young children in Pakistan: a clusterrandomised trial Lancet 382 29-40

Stoffel N U, Cercamondi C I, Brittenham G, Zeder C, GeurtsMoespot A J, Swinkels D W, Moretti D and Zimmermann M B (2017) Iron absorption from oral iron supplements given on consecutive versus alternate days and as single morning doses versus twice-daily split dosing in irondepleted women: two open-label, randomised controlled trials The Lancet Haematology 4 e524-e533

Thankachan P, Walczyk T, Muthayya S, Kurpad A V and Hurrell R F (2008) Iron absorption in young Indian women: the interaction of iron status with the influence of tea and ascorbic acid American Journal of Clinical Nutrition 87 881-886

World Health Organization (2011) Use of multiple micronutrient powders for home fortification of foods consumed by infants and children 6-23 months of age. Geneva. World Health Organization

World Health Organization (2016) Daily iron supplementation in infants and children. Geneva. World Health Organization

Zlotkin S, Newton S, Aimone A M, Azindow I, Amenga-Etego S, Tchum K, Mahama E, Thorpe K E and Owusu-Agyei S (2013) Effect of iron fortification on malaria incidence in infants and young children in Ghana: a randomized trial Journal of American Medical Association 310 938-947. 